05

\title{
Особенности магнитоэлектрического эффекта в структурах пермендюр-кварц-пермендюр в области электромеханического резонанса
}

\author{
() В.М. Лалетин ${ }^{1}$, Д.А. Филиппов ${ }^{2,9}$, Н.Н. Поддубная ${ }^{1}$, И.Н. Маничева ${ }^{2}$, G. Srinivasan $^{3}$ \\ ${ }^{1}$ Институт технической акустики НАН Беларуси, \\ Витебск, Беларусь \\ ${ }^{2}$ Новгородский государственный университет, Великий Новгород, Россия \\ ${ }^{3}$ Oakland University, Rochester, USA \\ ฯ E-mail: dmitry.filippov@novsu.ru
}

Поступило в Редакцию 28 декабря 2018г.

В окончательной редакции 5 февраля 2019 г.

Принято к публикации 6 февраля 2019г.

\begin{abstract}
Представлены результаты экспериментального исследования частотных и полевых зависимостей магнитоэлектрического эффекта в трехслойных структурах пермендюр-кварц-пермендюр в области электромеханического резонанса. Установлено, что в области электромеханического резонанса данные структуры имеют величину магнитоэлектрического коэффициента по напряжению и добротность, которые значительно превосходят таковые для аналогичных структур на основе цирконата-титаната свинца. В области электромеханического резонанса обнаружено аномальное поведение полевой зависимости магнитоэлектрического коэффициента по напряжению и добротности структуры, которое связано с отрицательным дельта- $E$-эффектом.
\end{abstract}

DOI: 10.21883/PJTF.2019.09.47706.17661

Магнитострикционно-пьезоэлектрические структуры привлекают к себе внимание тем, что обладают большой величиной магнитоэлектрического (МЭ) эффекта при комнатных температурах, что позволяет их рассматривать как перспективные материалы для создания устройств на его основе, таких как датчики магнитного поля, трансформаторы, СВЧ-аттенюаторы, перестраиваемые электрическим полем катушки индуктивности и др. [1-4]. Механизмом возникновения МЭ-эффекта в слоистых магнитострикционно-пьезоэлектрических структурах является механическое взаимодействие магнитострикционной и пьезоэлектрической компонент, вследствие чего величина эффекта прямо пропорциональна „произведению магнитострикции на пьезоэлектричество“. Согласно теории [5], величина МЭкоэффициента по напряжению пропорциональна произведению пьезомагнитострикционного коэффициента $q=\left.\frac{d \lambda}{d H}\right|_{H=H_{\text {bias }}}$ на пьезоэлектрический коэффициент $d$ и обратно пропорциональна значению диэлектрической проницаемости пьезоэлектрика. Для получения максимального значения МЭ-коэффициента по напряжению в качестве магнитострикционной фазы необходимо выбирать не просто материалы с большим коэффициентом магнитострикции, а материалы, у которых максимальна скорость изменения магнитострикции $\lambda$ при изменении магнитного поля, а в качестве пьезоэлектрической фазы - материалы с наибольшим отношением пьезоэлектрического коэффициента к диэлектрической проницаемости. Несмотря на то что пьезокерамика на основе цирконата-титаната свинца (ЦТС) обладает значительной величиной пьезомодуля $d \approx 100 \mathrm{pC} / \mathrm{N}$, она имеет одновременно и большое значение диэлектричес- кой проницаемости $\varepsilon=1750$, вследствие чего отношение пьезомодуля к диэлектрической проницаемости для нее равно $d / \varepsilon=0.0065 \mathrm{~m}^{2} / \mathrm{C}$. Для кварца с небольшим значением пьезомодуля $d=2,3 \mathrm{pC} / \mathrm{N}$ и диэлектрической проницаемостью $\varepsilon=4.5$ это отношение будет равно $d / \varepsilon=0.05 \mathrm{~m}^{2} / \mathrm{C}$, т.е. в 7.5 раз больше. Таким образом, использование кварца в качестве пьезоэлектрика для изготовления МЭ-структур должно приводить к бо́льшим значениям МЭ-коэффициента, чем для аналогичных структур на основе ЦТС. Кварц в отличие от ЦТС является монокристаллом, и при этом нет необходимости в его предварительной поляризации, как в случае пьезокерамики. Кроме того, пьезоэлектрические свойства ЦТС зависят от напряженности электрического поля, в результате чего на зависимости параметров структур от напряженности электрического поля наблюдается гистерезисная петля типа „бабочки“ [6], чего не наблюдается для структур на основе кварца. Ранее МЭ-эффект в структурах на основе кварца был исследован в работе [7], где в качестве магнитострикционной фазы был использован пермендюр, а сами структуры изготавливались методом склеивания. Для планарных колебаний трехслойной структуры в области электромеханического резонанса было получено максимальное значение МЭ-коэффициента по напряжению (MEVC), равное $\alpha_{E, \max }=175 \mathrm{~V} /(\mathrm{cm} \cdot \mathrm{Oe})$ при добротности $Q=35$.

Цель настоящей работы состоит в изготовлении трехслойных структур пермендюр-кварц-пермендюр и изучении зависимости их магнитоэлектрических характеристик и добротности от поля подмагничивания в области электромеханического резонанса. Актуальность этого 
исследования заключается в том, что в магнитном поле возникает изменение модуля Юнга, или так называемый дельта- $E$-эффект, в результате чего происходит сдвиг частоты электромеханического резонанса, который может лежать в основе создания сверхчувствительных датчиков постоянного магнитного поля [8]. В работе экспериментально установлено, что на полевой зависимости MEVC и добротности имеются особенности, обусловленные наличием отрицательного дельта- $E$-эффекта.

В качестве пьезоэлектрика для изготовления структур использовались образцы, вырезанные из пластины кварца $(X$-срез $)$ в форме параллелепипеда размером $20 \times 4.5 \times 0.5 \mathrm{~mm}$, с обеих сторон к которым были приклеены магнитострикционные пластины из пермендюра размером $20 \times 4.5 \times 0.16 \mathrm{~mm}$. МЭ-эффект исследовался методом регистрации переменного электрического напряжения на образце при помещении его в постоянное подмагничивающее поле напряженностью $H_{\text {bias }}$ и переменное магнитное поле $H$, направленные вдоль длинной стороны образца. Исследования показали, что частотная зависимость МЭ-эффекта имеет ярко выраженный резонанс, амплитуда и частота которого изменяются при изменении поля подмагничивания. Низкочастотное значение MEVC $\alpha_{E}^{\text {Low }} \approx 1.4 \mathrm{~V} /(\mathrm{cm} \cdot \mathrm{Oe})$, максимальное резонансное значение коэффициента равно $\alpha_{E, \max }=740 \mathrm{~V} /(\mathrm{cm} \cdot \mathrm{Oe})$ при добротности $Q \approx 1400$, определенной как отношение резонансной частоты к полуширине резонансной линии на уровне 0.7. Хотя низкочастотное значение для данной структуры ниже, чем для структуры, приведенной в работе [7], ее резонансное значение в 4 раза превышает величину, полученную в [7]. Это объясняется высокой добротностью полученной структуры благодаря более совершенной технологии изготовления. Несмотря на то что добротность структуры имеет довольно высокое значение, в 10 раз превышающее величину для структур на основе ЦТС [9], однако ее значение все-таки в 7 раз меньше, чем для структур на основе кварца, полученных методом электролитического осаждения никеля [10].

Благодаря высокой чувствительности результаты, полученные при исследовании МЭ-эффекта в области электромеханического резонанса, могут служить базой для исследования других эффектов, таких как магнитострикция и дельта- $E$-эффект. Как было установлено на опыте, при помещении структуры в магнитное поле происходит сдвиг частоты электромеханического резонанса, который обусловлен изменением модуля Юнга. Связь изменения модуля Юнга $\Delta^{m} Y$ магнетика со сдвигом частоты резонанса, согласно [5], определяется соотношением

$$
\frac{\Delta^{m} Y}{{ }^{m} Y}=2 \frac{\Delta f_{\text {res }}}{f_{\text {res }}} \frac{\left({ }^{p} Y^{p} t+{ }^{m} Y 2^{m} t\right)}{{ }^{m} Y 2^{m} t},
$$

где $f_{\text {res }},{ }^{m} Y$ - значения резонансной частоты и модуля Юнга при нулевом магнитном поле, ${ }^{p} Y-$ модуль Юнга пьезоэлектрика, ${ }^{m} t,{ }^{p} t-$ толщина магнетика и пьезоэлектрика соответственно.

На рис. 1 приведен график относительного изменения модуля Юнга, полученный на основе измене-

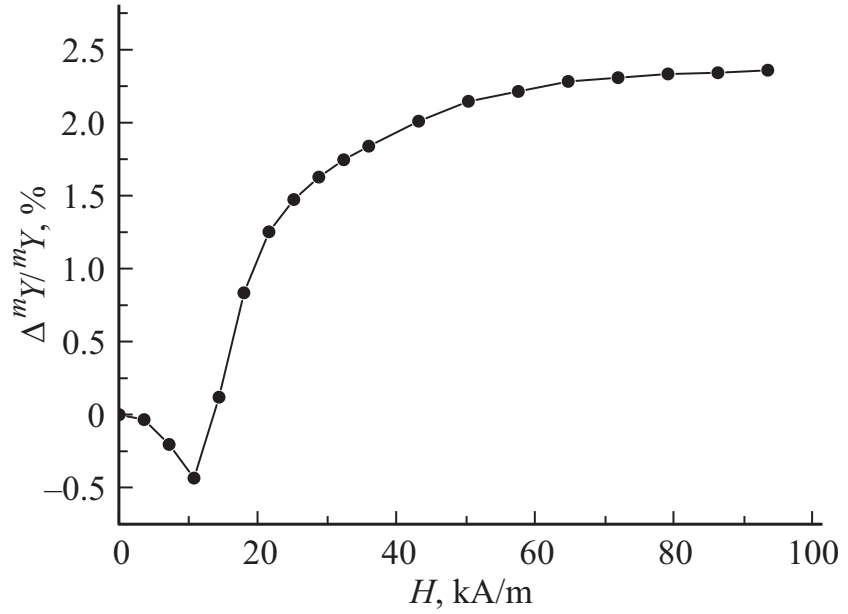

Рис. 1. Зависимость относительного изменения модуля Юнга от поля подмагничивания.

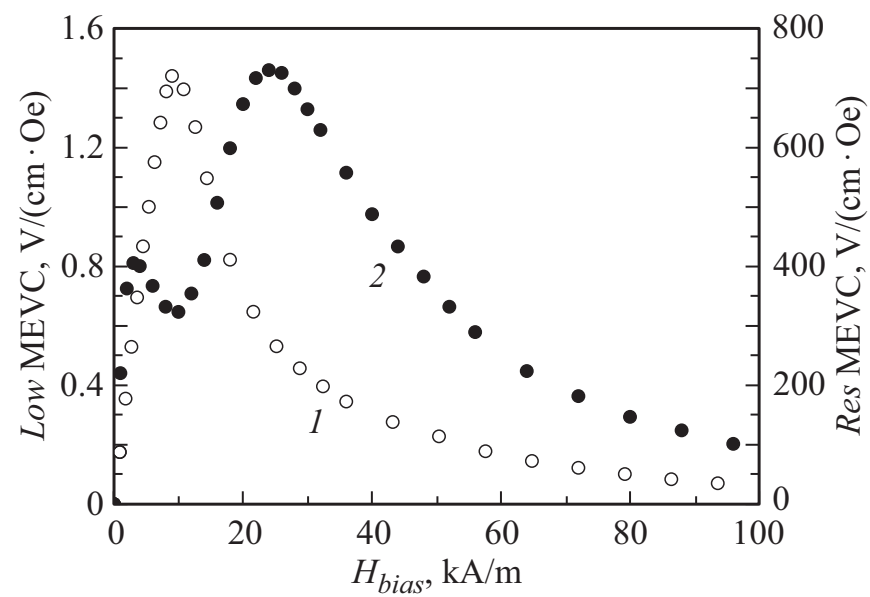

Рис. 2. Полевые зависимости низкочастотного (1) и резонансного (2) МЭ-коэффициента по напряжению.

ния резонансной частоты структуры под действием магнитного поля. Как видно из рисунка, в области магнитных полей от 0 до $12 \mathrm{kA} / \mathrm{m}$ наблюдается отрицательный дельта- $E$-эффект, затем модуль Юнга возрастает и выходит на насыщение в магнитных полях свыше $40 \mathrm{kA} / \mathrm{m}$. Наличие отрицательного дельта- $E$-эффекта приводит к аномальной полевой зависимости MEVC. На рис. 2 представлена зависимость MEVC от поля подмагничивания на низкой частоте $(1 \mathrm{kHz})$ и в области электромеханического резонанса. В области электромеханического резонанса измерения MEVC осуществлялись путем непрерывной подстройки на резонансную частоту. Как следует из рисунка, полевые зависимости MEVC в низкочастотной области спектра и в области электромеханического резонанса существенно различаются. В низкочастотной области спектра полевая зависимость MEVC в точности повторяет полевую зависимость пьезомагнитного коэффициента $q=\left.\frac{d \lambda}{d H}\right|_{H=H_{\text {bias }}}$ 


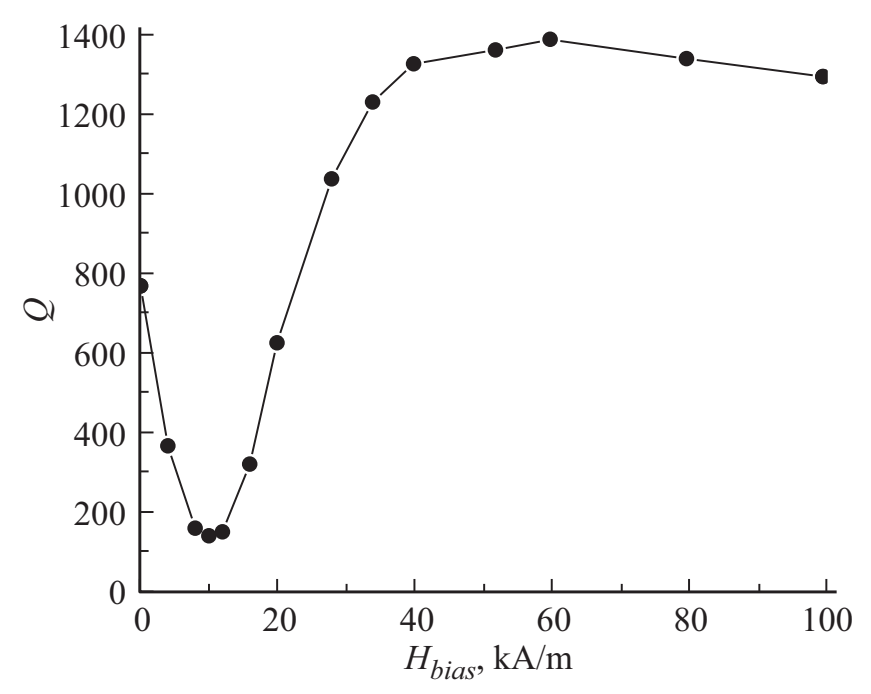

Pис. 3. Зависимость добротности структуры от поля подмагничивания.

от магнитного поля. Аналогичная зависимость MEVC имеет место и вдали от резонанса при частотах выше резонансной частоты. В области электромеханического резонанса наблюдается аномальная зависимость MEVC от напряженности поля подмагничивания. Это связано с тем, что резонансное значение MEVC пропорционально произведению низкочастотного значения на добротность структуры. На рис. 3 приведена зависимость добротности структуры, определенной как отношение частоты резонанса к ширине резонансной линии на уровне 0.7 , от поля подмагничивания. Из сопоставления данных, представленных на рис. 1 и 3, следует, что в области магнитных полей от 0 до $40 \mathrm{kA} / \mathrm{m}$ наблюдается изменение модуля Юнга пермендюра и, как следствие, изменение добротности структуры, которое приводит к аномальному поведению полевой зависимости MEVC в области электромеханического резонанса.

Таким образом, трехслойные структуры пермендюр-кварц-пермендюр обладают величиной МЭ-коэффициента по напряжению и добротностью, в несколько раз превышающими таковые для аналогичных структур на основе пьезокерамики ЦТС. В области магнитных полей от 0 до $40 \mathrm{kA} / \mathrm{m}$ наблюдается изменение модуля Юнга, приводящее к уменьшению добротности структуры, вследствие чего в области электромеханического резонанса возникает участок аномальной полевой зависимости МЭ-коэффициента по напряжению.

\section{Финансирование работы}

Работа выполнена при поддержке гранта совместного конкурса РФФИ-БРФФИ (российский проект № 18-52-00021 и белорусский проект № Ф18Р-300).

\section{Список литературы}

[1] Leung C.M., Li J., Viehland D., Zhuang X. // J. Phys. D: Appl. Phys. 2018. V. 51. P. 263002.

[2] Song C., Cui B., Li F., Zhou X., Pan F. // Prog. Mater. Sci. 2017. V. 87. P. 33-82.

[3] Sadovnikov A.V., Grachev A.A., Beginin E.N., Sheshukova S.E., Sharaevskii Yu.P., Nikitov S.A. // Phys. Rev. Appl. 2017. V. 7. P. 014013.

[4] Vopson M.M. // Crit. Rev. Solid State Mater. Sci. 2015. V. 40. N 4. P. 223-250.

[5] Filippov D.A., Laletin V.M., Galichyan T.A. // Appl. Phys. A. 2014. V. 115. P. 1087-1091.

[6] Zhang J., Chen D., Filippov D.A., Li K. , Zhang Q., Jiang L., Zhu W., Cao L., Srinivasan G. // Appl. Phys. Lett. 2018. V. 113. P. 113502.

[7] Sreenivasulu G., Petrov V.M., Fetisov L.Y., Fetisov Y.K., Srinivasan G. // Phys. Rev. B. 2012. V. 86. P. 214405.

[8] Li M., Matyushov A., Dong C., Chen H., Lin H., Nan T., Qian Z., Rinaldi M., Lin Y., Sun N.X. // Appl. Phys. Lett. 2017. V. 110. P. 143510.

[9] Jia Y., Zhou W., Ma K., Liu Y. // Appl. Sci. 2015. V. 5. P. 587594.

[10] Лалетин В.М., Филиппов Д.А., Мозжсаров С.Е., Маничева И.Н. // Письма в ЖТФ. 2018. Т. 44. В. 7. С. 16-22. 